Bull. Mater. Sci., Vol. 8, No. 2, May 1986, pp. 193-198. (C Printed in India.

\title{
Computer-aided composition-treatment-structure-property correlation studies in steels
}

\author{
K VIJAYARAJU and E S DWARAKADASA \\ Department of Metallurgy, Indian Institute of Science, Bangalore 560012, India
}

\begin{abstract}
Internal structure of materials uniquely decides their properties. The structure is a complicated function of composition and thermal and/or mechanical treatment. Inter-relation is so complex that a highly generalized correlation is very difficult. Steel is a very good example to illustrate this complexity. Advent of mini- and microcomputers have now paved way for handling such multiparametric problems in a more rational way, with greater ease and increased confidence. This paper is an attempt to develop a computer software which will assist the user in three different ways: (a) to determine the treatments that will generate a desired structure, when compositions are known; (b) to determine composition limits within which desired structure will result having defined the treatments, and (c) to predict structures that can be generated when composition and treatments are limited. This program has immense utility of (i) best use of available inventory, (ii) reduction of standards, varieties and inventory and (iii) most importantly to decide the best purchase based on treatment limitations in the shop. $A$ large data bank is being built to support the program.
\end{abstract}

Keywords. Steel; property; structure; correlation; software; computer handling.

\section{Introduction}

Microstructure plays a very important role in deciding the properties of a material. Microstructures can be altered by changing material composition and by imparting suitable thermal and/or mechanical and thermomechanical treatments. The problem of alloy chemistry is complex and treatment variables are many. The case of ferrous materials, steels in short, is a typical example in hand. Investigations over the past several centuries have generated innumerable steel compositions and treatments. The result, as we see today, is the huge inventory and list of standards the materials engineer has to cope up with. There is an urgent need to rationalize the picture and many attempts are being made. Structure property correlation studies have been looked into in great detail to derive constitutive but empirical relationships that may be used to predict the properties. However, these studies are of limited application as they are governed by severe restrictions. The advent of mini- and microcomputers has now changed our approach to the problem and further offers tremendous possibilities. It only needs a serious investigation to utilize the data available to fit in meaningful relationships into an objectively built program. To take the specific example of steels, problems may be defined in terms of a few typical goal oriented questions.

(i) Property limits for a particular application are defined, what would constitute a set of ideal conditions of composition, structure and treatment that will satisfy this situation?

(ii) A given set of steel varieties are available in the yard. What would be the minimum and maximum properties that can be achieved making use of all applicable treatments? What would be the microstructure in each case? 
(iii) A certain microstructure is to be generated. What are the steel compositions and treatments that will result in this microstructure?

Even with these three goals, the dimension of the problem becomes huge and underlines the need for computer handling of the problem. A long term plan to build a software facility to handle this problem has been initiated (Vijayaraju 1984). This paper describes the first phase of the development of an interactive program in which the composition, microstructure and treatment are interrelated to yield the mechanical properties. The program has been mainly developed based on a number of empirical relationships that relate composition and/or structure with the resulting properties, and hence is applicable only within certain limiting conditions that have been imposed such as medium carbon steels, single continuous cooling, straight forward microstructures, etc. The long term plan is to develop a set of programs in all dimensions to make it applicable to all steels universally.

\section{Software description}

The methodology of the development of the software is shown in figure 1. As a first step, the composition data are fed into the program. Based on this data the program calculates the various transformation temperatures $M_{s}, A C_{1}, A C_{3}$ using equations (1)-(3) (Cias 1977).

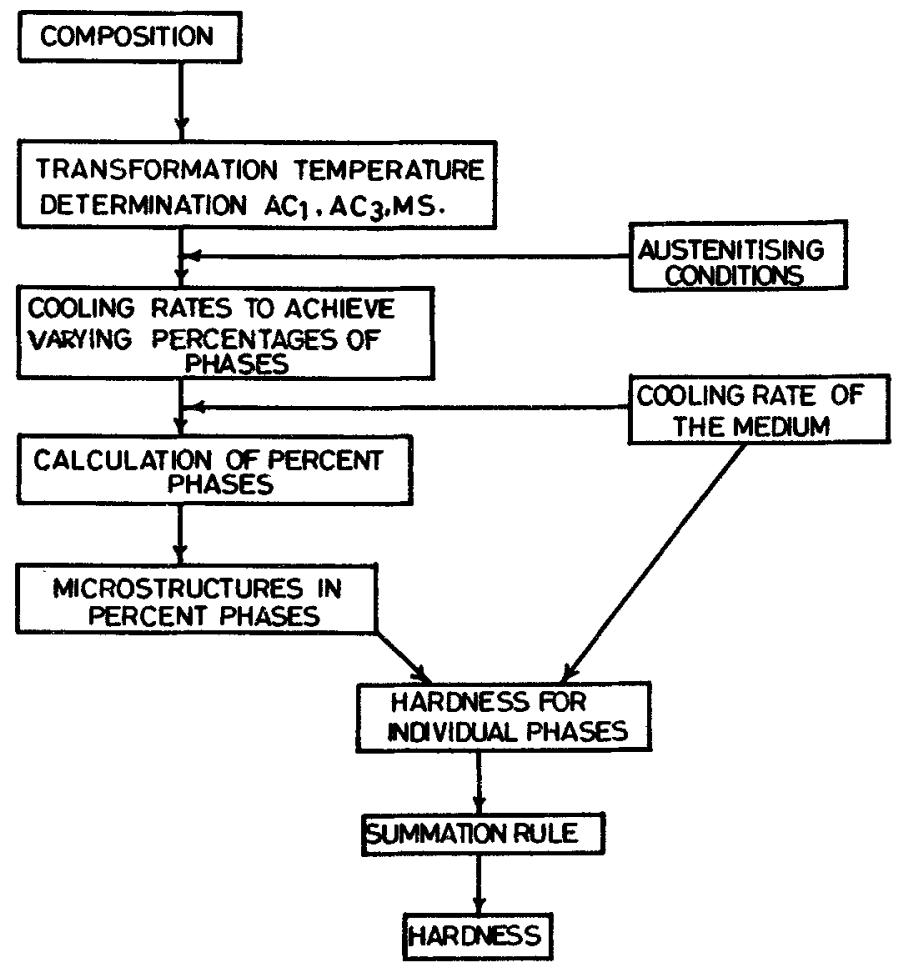

Figure 1. Methodology of the software development. 


$$
\begin{aligned}
A C_{1} & =712+20.4 \mathrm{Si}-17.8 \mathrm{Mn}-9.8 \mathrm{Mo}+11.9 \mathrm{Cr}-19 \cdot 1 \mathrm{Ni} \\
A C_{3} & =871-254.4 \mathrm{C}+51.7 \mathrm{Si}-14.2 \mathrm{Ni} \\
M_{s} & =531-39.2 \mathrm{C}-43.3 \mathrm{Mn}-16.2 \mathrm{Cr}-21.8 \mathrm{Ni}
\end{aligned}
$$

Then from these results the user can prefer the austenitization temperature and the time of austenitization from the section size and geometry. Now to take care of the grain growth during the austenitization, a parameter called 'austenitization parameter', $P_{A}$, is defined and can be calculated from the equation given below (Maynier et al 1978):

$$
P_{A}=\left[1 / T-\frac{n R}{H} \log \left(t / t_{0}\right)\right]^{-1},
$$

where $T$ is the austenitization temperature $\left({ }^{\circ} \mathrm{K}\right), R$ is the gas constant, $H$, the activation energy for the grain growth and $t, t_{0}$ is the time of austenitization and unit time. Using the data on composition and transformation in the following set of equations the cooling rates to obtain a particular combination of percentage phases are calculated (Maynier et al 1978)

$$
\begin{aligned}
\log V_{1}= & 9.81-(4.62 \mathrm{C}+1.05 \mathrm{Mn}+0.54 \mathrm{Ni}+0.50 \mathrm{Cr}+0.66 \mathrm{Mo} \\
& \left.+0.00183 P_{A}\right) \\
\log V_{2}= & 10.17-(3.80 \mathrm{C}+1.07 \mathrm{Mn}+0.70 \mathrm{Ni}+0.57 \mathrm{Cr}+1.58 \mathrm{Mo} \cdot \\
& \left.+0.0032 P_{A}\right) \\
\log V_{3}= & 6.36-(0.43 \mathrm{C}+0.49 \mathrm{Mn}+0.78 \mathrm{Ni}+0.27 \mathrm{Cr}+0.38 \mathrm{Mo} \\
& \left.+2 \sqrt{\mathrm{Mo}}+0.0019 P_{A}\right) \\
\log V_{190}= & 8.76-(4.04 \mathrm{C}+0.96 \mathrm{Mn}+0.49 \mathrm{Ni}+0.58 \mathrm{Cr}+0.97 \mathrm{Mo} \\
& \left.+0.0010 P_{A}\right) \\
\log V_{290}= & 10.55-(3.65 \mathrm{C}+1.08 \mathrm{Mn}+6.77 \mathrm{Ni}+0.61 \mathrm{Cr}+1.60 \mathrm{Mo} \\
& \left.+0.0032 P_{A}\right) \\
\log V_{390}= & 7.59-(9.38 \mathrm{C}+0.35 \mathrm{Mn}+0.93 \mathrm{Ni}+0.11 \mathrm{Cr}+2.31 \mathrm{Mo} \\
& \left.+0.0033 P_{A}\right) \\
\log V_{250}= & 8.50-(4.12 \mathrm{C}+0.86 \mathrm{Mn}+0.57 \mathrm{Ni}+0.41 \mathrm{Cr}+0.94 \mathrm{Mo} \\
& \left.+0.0012 P_{A}\right) \\
\log V_{250}= & 8.74-(2.23 \mathrm{C}+0.86 \mathrm{Mn}+0.56 \mathrm{Ni}+0.59 \mathrm{Cr}+1.60 \mathrm{Mo} \\
& \left.+0.0032 P_{A}\right)
\end{aligned}
$$

where $V_{1}=$ minimum quench velocity to attain a complete martensitic structure, $V_{2}=$ critical cooling velocity resulting in entirely bainitic structure with small amounts of martensite, $V_{3}=$ critical cooling velocity to achieve a completely annealed structure, i.e., ferrite and pearlite, $V_{190}=$ critical cooling velocity giving $10 \%$ bainite and $90 \%$ martensite, $V_{290}=$ critical cooling velocity giving $10 \%$ ferrite-pearlite and $90 \%$ bainite, $V_{390}=$ critical cooling velocity giving $90 \%$ ferritepearlite and $10 \%$ bainite, $V_{150}=$ critical cooling velocity giving $50 \%$ martensite and $50 \%$ bainite, $V_{250}=$ critical cooling velocity giving $50 \%$ bainite and $50 \%$ ferrite-pearlite.

From the various critical cooling rates to attain different discrete combinations of martensite, bainite and ferrite-pearlite, two second order polynomial equations have been fitted. Using this, the intermediate combinations of different phases are calculated 
for any cooling rate. This results in the final microstructures in terms of percentage of martensite, bainite and pearlite. Equations (13)-(15) are taken from the literature (Maynier et al 1978) for the determination of hardness values of the individual phases, i.e., $100 \%$ martensite or $100 \%$ bainite or $100 \%$ ferrite-pearlite. The hardness of the final microstructure is calculated using the summation rule:

$$
\begin{aligned}
H V M= & 127+949 \mathrm{C}+27 \mathrm{Si}+11 \mathrm{Mn}+8 \mathrm{Ni}+16 \mathrm{Cr}+21 \log (\mathrm{Cv}) \\
H V B= & 323+185 \mathrm{C}-330 \mathrm{Si}+153 \mathrm{Mn}+65 \mathrm{Ni}+144 \mathrm{Cr}+194 \mathrm{Mo} \\
& -\log \mathrm{Cv}(89+53 \mathrm{C}-55 \mathrm{Si}-22 \mathrm{Mn}-10 \mathrm{Ni}-20 \mathrm{Cr}-30 \mathrm{Mo}) \\
H V(F+P)= & 42+23 \mathrm{C}+53 \mathrm{Si}+30 \mathrm{Mn}+12 \cdot 6 \mathrm{Ni}+7 \mathrm{Cr}+19 \mathrm{Mo} \\
& -\log \mathrm{Cv}(10-19 \mathrm{Si}+4 \mathrm{Ni}+8 \mathrm{Cr}+130 \mathrm{~V})
\end{aligned}
$$

$C v=$ cooling velocity, $H V M=$ hardness of $100 \%$ martensitic structure, $H V B$ $=$ hardness of entirely bainitic structure, $H V(F+P)=$ hardness of completely annealed structure, i.e., fully ferrite-pearlitic structure.

A graphical representation of the variation of the percentage of each phase with the cooling rates is shown in figure 2. Similarly the variation of the hardness values ( $V H N$ ) with the cooling rate is shown in figure 3 .

\section{Limitations}

The validity of this study is limited to the following ranges of composition and conditions of austenitization and tempering.

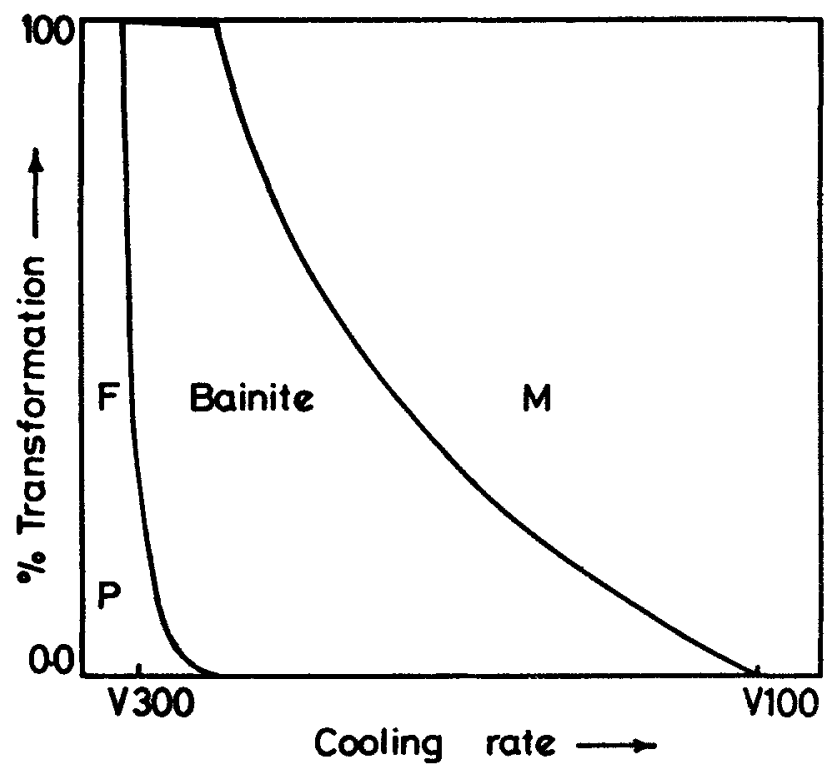

Figure 2. Identification of product as a function of cooling rate. 


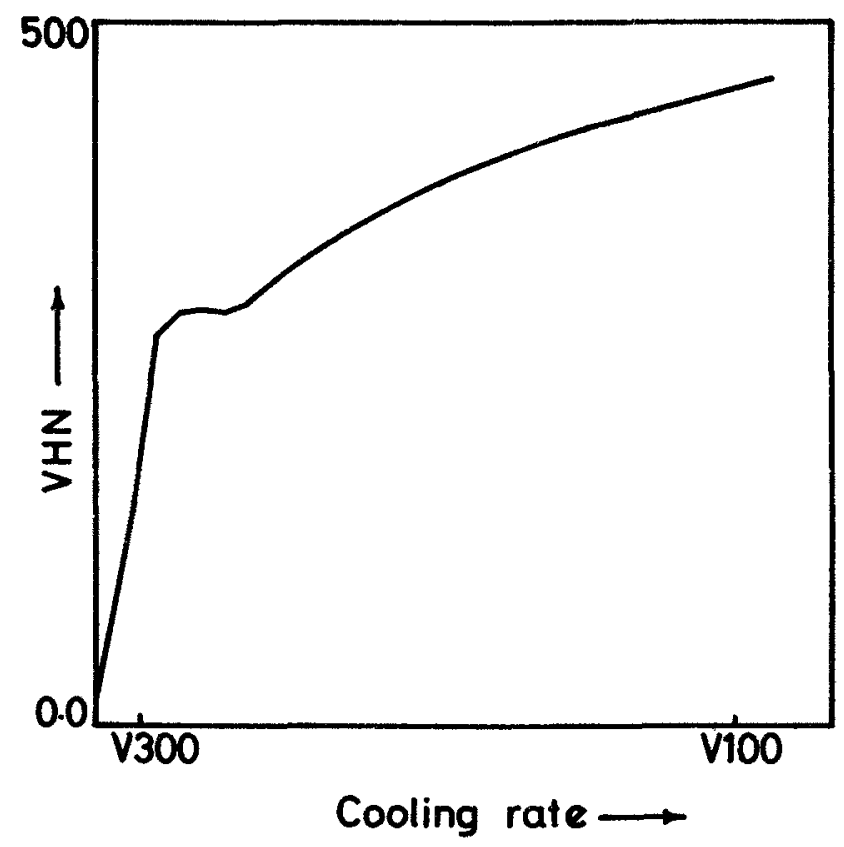

Figure 3. Variation of hardness of steel as a function of cooling rate.

\subsection{Composition range: (weight $\%$ )}

$$
\begin{aligned}
& 0.1<\mathrm{C}<0.5 ; \mathrm{Mn}<2 ; \mathrm{Ni}<4 ; \mathrm{Cr}<3 ; \mathrm{Si}<1 ; \mathrm{Mo}<1 ; \\
& \mathrm{V}<0.2 ; \mathrm{Cu}<0.5 ; \mathrm{Mn}+\mathrm{Ni}+\mathrm{Cr}+\mathrm{Mo}<5 ; 0.01<\mathrm{Al}<0.05
\end{aligned}
$$

\subsection{Austenitizing conditions}

It should be between $800^{\circ} \mathrm{C}$ for $1 \mathrm{hr}$ and $1100^{\circ} \mathrm{C}$ for $1 \mathrm{hr}$. Tempering conditions should be between $500^{\circ} \mathrm{C}-1 \mathrm{hr}$ and $700^{\circ} \mathrm{C}-200 \mathrm{hr}$. Intercritical treatment is not included. Alloying additions like $\mathrm{Nb}, \mathrm{Ti}, \mathrm{B}$ and $\mathrm{Zr}$ are not included in this study.

\section{Conclusion}

The present study opens up many physical and mechanical metallurgical aspects of steels for theoretical predictions. The predicted results are comparable with the experimental points within an allowable variation. Although the flow chart shown in figure 1 gives the methodology of the present study, it is possible to trace back the path that will result in the optimization of composition and treatment for a required set of mechanical properties. Presently this work is being projected to cope up with the variety of steels and extending the operating range of composition and treatment conditions, although limited by certain factors. The value of the prediction will be greatly enhanced if the microstructure is simulated on the Visual Display Unit (vDU) for the given set of compositions and treatments. 


\section{References}

Cias W W 1977 Phase transformation kinetics of selected wrought structural steels, Report, Climax Molybdenum Co., Greenwich, Connecticut, USA

Maynier Ph, Dollet J and Bastien P 1978 Proc. Symp. Met. Soc. AIME, (Philadelphia: AIME) p. 163

Vijayaraju K 1984 B E Project Report, Department of Metallurgy, Indian Institute of Science, Bangalore 